\title{
E-tailing in Australia: A preliminary analysis of David Jones
}

\author{
Jun Xu, Xiangzhu Gao and John Hammond \\ Southern Cross University \\ Southern Cross Drive, Bilinga, Queensland 4225, Australia \\ Email: john.b.hammond@scu.edu.au
}

\begin{abstract}
Compared with other countries, especially China, United States, United Kingdom, Japan and Germany, Australia's online retail fall behind in terms of both its sale and percentage contribution to the total retail. This paper analyses David Jones, which is typical of large department store chains, and Australian e-tailing environment as a case study to identify enablers for and obstacle to the advancement of e-tailing in Australia. Based on the analysis, the paper provides David Jones with recommendations on internal improvement, supply chain, customer relationship, and adoption of emerging technologies. Future research will be conducted to investigate if the recommendations are also applicable for other Australian retailers.
\end{abstract}

Keywords: E-tailing, Click-and-Mortar, Omni-Channel, David Jones, Department Store, Australia.

\section{Introduction}

The Internet and emerging digital technologies have had a profound impact on both consumers' shopping experience and behavior and retailers' business operations. Consumers can search for and compare needed products or services easily, and can easily switch to other retailers with a few mouse clicks. Retailers can collect and analyse customer data online for mass customization and personalization to improve customer relationships. The Internet also creates opportunities for new products or services, instant interaction, multimedia communication and ubiquitous access. In the upstream of industry chains, retailers can collaborate and cooperate with their suppliers for procurement and logistics. Moreover, the Internet and telecommunication networks improve strategic alliance of retailers with their partners, affiliates and other stakeholders. According to Ecommerce Foundation, ${ }^{1}$ global B2C e-commerce sales have increased steadily since 2010. In the last five years, global B2C ecommerce growth were from $17.5 \%$ to $28.5 \%$. Available data shows that Australia's growth was 14.6\% in 2013 and $15.7 \%$ in 2015 .

In Australia, David Jones is an upmarket department store targeting mid-to-upper income customers.
Founded in 1838, it has a long and established history and brand, and is Australia's oldest department store and the oldest department store in the world still trading under its original name. ${ }^{2,3}$ With rich retail experience, David Jones has developed its e-tailing platforms, supply networks, and loyal customer base. Currently, David Jones is a clicks-and-mortar e-tailer of more than 43 stores in Australia and New Zealand, 2 warehouse outlets and David Jones Online., ${ }^{2,4}$ It has been working on its omni-channel strategy in recent years. Currently David Jones is trying to achieve $10 \%$ revenue from online sales, while many of its international competitors have already achieved between $15 \%$ to $20 \%$ revenue from online sales.

This paper analyses David Jones as a clicks-andmortar e-tailer and the Australian e-tailing environment to identify enablers for and obstacle to the advancement of e-tailing in Australia. Based on the analysis, the paper provides David Jones with recommendations for future directions.

\section{External Business Environment}

\subsection{Retail environment in Australia}

In recent years, the retail landscape in Australia has been changing dramatically, with uncertain economic 
outlook, fluctuations of the Australian dollar, the increasing popularity of specialty stores and brandfocused businesses, the disruption of the Internet on retail, foreign competition and arrival of international retailers to Australian shores, and constantly changing consumer tastes and needs., ${ }^{5,6,8}$ Like other markets, online retail has been growing significantly, although it still only accounts for a small proportion of the total retail in Australia. Currently, annual online retail sale is A $\$ 20$ billion, accounting for less than $7 \%$ of total retail in Australia. ${ }^{9}$ As a result of Australia's geographic challenges and the existing logistic infrastructure, customers have to put up with slow shipping since there is limited domestic competition even though there exists some international competition. In the UK or US, an order could reach the customer's doorstep in around 2 days, but it takes longer in Australia. Slow delivery and high shipping costs have been an obstacle to e-tailing operations in Australia. Australian retailers and their logistic and delivery partners need to improve their logistic and delivery practices with faster, cheaper and more reliable services. Facing the challenges from international e-tailers or marketplaces, (e.g. Amazon and Alibaba) Australian e-tailers could focus on populated cities, coastal areas and major/large towns as the first step, ${ }^{10}$ and work on differentiated products and product bundlings and heavy and bulky items that Amazon is not interested in shipping. ${ }^{11}$ Australian e-tailers should build and enhance consumer trust of the local market, offer in-store pickup and advice for online orders.

Meanwhile it is also argued that the retail conditions in Australia are challenging. ${ }^{12}$ There are too many department stores in Australia, which have been struggling with profitability. ${ }^{6}$ In addition, due to a shrinking middle class, increasing debt, and cost of living pressures Australian consumers have reduced their spending on such items as fashion, clothes and shoes. ${ }^{13,14}$ While the Australian economy has a positive outlook, consumers may not be willing to keep on paying high retail prices caused by over-inflated rents and expensive labor costs as well as productivity and efficiency issues. ${ }^{13}$ Also, it is suggested that the most dominant retail customer segment by 2020 will be millennials who very much embrace the digital world. Millennials may not shop frequently, but they do enjoy the shopping experience, whether in store or online. Customers value shopping experiences in any channels. ${ }^{9}$
Retailers need to acknowledge this and cater for their high shopping experience expectations and use both digital and non-digital assets and resources to influence and facilitate their decision making and purchases. In-store shopping experience and transactions would be more appealing if the value proposition of visiting the store is good enough. ${ }^{9}$ Not all customers want to get a product quickly online, and many customers just want to spend some time in the store for leisure and for socialization. ${ }^{15}$

\subsection{Competition}

While the fierce competition in the industry could lead to gains for consumers, the Internet reduces entry barriers and differences among competitors. Anyone can set up an online business with a computer, an Internet connection, and a website, especially when cloud computing becomes the norm. Smaller and newer online businesses can compete with larger and more established players. However, it takes time and resources to develop quality retailers with wellestablished brands, supply networks, warehouse outlets, retail experience, customer base and loyalty. The resources are most needed for small and medium players especially pure online players. For example, the lack of a physical outlet and presence is a significant weakness for pure online retailers. International leading retailers such as Amazon and Dell have taken the lead in having physical stores/presence for such reasons as catering for customers who are not used to online shopping, improving customer service or interaction with customers, and combining strengths of digital and non-digital channels. According to a recent CBA report, ${ }^{16} 18 \%$ of pure online retailers are planning to have physical outlets by early 2017 .

Currently less than $10 \%$ retail is done online, ${ }^{17}$ while $50.3 \%$ of Australians shopped online ${ }^{18}$ because of the high penetration of the Internet and adoption of mobile devices. At this early stage of e-tailing, David Jones faces:

- traditional competition from domestic and international retailers and brands, including Myer, OZSales, Showpo, Dealsdirect, Kogan, ShoesofPrey, Missguided, Thesurfstitich, ASOS, Net-O-Pointer, Zara, Hugo Boss, Lacoste, Burberry, and many others,

- non-traditional competition from resource-rich or technology-enabled firms or firms with a large 
user-base, including venture capital firms, telecommunication companies, ICT firms, online services firms, social media firms, online communities, online marketplaces, marketing and adverting networks, transportation and distribution firms, and others that could enter the B2C e-tailing market.

\subsection{Upcoming Arrival of Amazon in Australia}

Amazon is establishing its warehouses in Australia to fulfil its bricks-and-mortar business in this country. It is expected that Amazon can provide a wider range of products and services at cheaper prices than many Australian retailers and ship them faster than before. However, Amazon faces high logistic and delivery costs as Australia is a large country with a small population. Other challenges for Amazon include relatively small market, different consumer habits, need for loyalty creation, payment methods, absence of physical stores, and risk perceptions. ${ }^{19,20}$.

The arrival of Amazon could have a more profound impact on pure online retailers in Australia. ${ }^{21}$. Traditional department stores like David Jones need to maximize the value of their physical stores, leverage their specific competitive advantages and adapt to changing market conditions. ${ }^{22}$ Like other retailers, David Jones has to provide a selection of merchandise with competitive prices, develop and implement an effective omni-channel strategy and seamlessly incorporate the online and offline activities to achieve harmony. David Jones should make use of online resources to leverage their brand equity and engage their customers to drive them to the store. David Jones needs to provide online personalized services to simulate human-led in-store experiences, which could not be replicated electronically in the online environment. ${ }^{9,23}$

It can be reasonably expected that some retail sectors could be presented with tough competition with the arrival of Amazon, including small and nonexpensive consumer electronics, fashion, clothing and accessories, and groceries. ${ }^{24}$ David Jones could particularly feel the impact in the categories of consumer electronics and fashion, clothing, shoes and accessories.

\subsection{Possible Merger of David Jones and Myer}

Myer is a direct competitor of David Jones in the domain of department stores in Australia. The merger of
David Jones and Myer has been the subject of discussion in the retail industry in recent years. Some pro-merger arguments ${ }^{5,6,25,26,27,28}$ include:

- Australian market cannot viably support multiple large department stores and only one large chain can be financially viable.

- Both David Jones and Myer have been struggling in recent years as a result of the changing retail landscape.

- The merger could strengthen the department store chains and enable them to more effectively deal with domestic and international online and offline competition.

- The merger could provide opportunities to maximize the value of their property assets.

- The merged two brands could serve a boarder customer base and provide customers with more choices and better shopping experiences.

- The merger is possible based on the current market conditions.

- The merger could bring in about A\$85 million annual cost savings within 3 years, arising from head office cost savings, efficient sourcing and procurement, savings in advertising, back-end systems and store closing, staffing and operation costs. The merger also could generate more than A $\$ 900$ million of value to shareholders of David Jones and Myer.

Some reasons against the merger ${ }^{25,26,27,28,29}$ are:

- Australia has strong regulatory rules on anticompetitive behavior. There may be challenges in getting the approval to merge from the Australian Competition and Consumer Commission (ACCC).

- Given the intense competition and the size of Australian market, only one (not both or combined two) upmarket-type department store chains is needed.

- The proposed cost savings resulting from the merger may not be retained and/or realized, as it may require additional resources to align systems, structure and culture after the merger, and the exiting of leases will be very costly.

- $\quad$ The merger may not create a significantly larger customer base since some customers shop at both David Jones and Myer.

- $\quad$ There are doubts whether the merger could bring benefits to shareholders especially if the main 
motivation of the merger is for cost cutting and not revenue growth.

For David Jones, however, the authors argue that it stands to benefit from focusing on becoming a master clicks-and-mortar e-tailer and achieving excellence in the execution of omni-channel strategy until the possible merger is on the table.

\section{Internal Operating Environment}

As indicated in Section 1, David Jones' strengths include long and established history and brand, existing supply networks, more than 43 stores and 2 warehouse outlets in Australia and New Zealand, a rich retail experience, and an established customer base and loyalty. Conversely, issues, concerns and weaknesses of David Jones ${ }^{12,30,31,32,33,34,35}$ include

- declining sale performance - Recent drop in sales revenue due to high discounting, the closure of Dick Smith and some David Jones stores, and a poorly executed private label strategy,

- $\quad$ poor record of online strategy and implementation - David Jones responds slowly to the attack and invasion of new online retailers and cannot rely on brand loyalty alone. David Jones opened its online store in 2000, but shut it down in 2003 and only reopened it in 2010, thereby missing prime opportunities of leading the competition. David Jones should review its online strategy to improve its execution.

- $\quad$ loss of talent management - David Jones recently decided to relocate its headquarters from Sydney to Melbourne. The relocation may result in the loss of talent staff, especially senior managers.

- $\quad$ outdated system - Its systems are comparatively out of date and face the typical challenge of lack of interoperability. There is no consolidated and integrated view for products and customers. Its website is not dynamic and does not perform well in personalization and customization.

- David Jones should create an innovation culture and adopt new technology.

- $\quad$ unstable top management teams - e.g., its former CEO Paul Zahra had resigned twice.

- While David Jones is aiming for $10 \%$ revenue from online sales in the future, many of its international competitors have already achieved between $15-20 \%$ revenue from online sales.
- the website is very cluttered and offers very little value proposition with menus at both top and bottom of the webpage.

- $\quad$ lack of investment in human resource - There is a lack of staff training and staff career advancement planning and commitments.

- $\quad$ poor integration of online and offline channels There are reports that online displayed products were not available in stock, and online orders were not delivered on time.

- deteriorating in-store service - This is reflected in poor customer experiences in recent years.

\section{Outlook}

\subsection{Future Directions and Opportunities}

The new management team of David Jones has suggested the following initiatives to transform David Jones ${ }^{3,15,36,37}$

- increasing sales of higher margin private label products or David Jones' own brands from the present $3 \%$ to $20 \%$ of sales,

- targeting David Jones credit cards holders and members of the loyalty program,

- $\quad$ stocking more Country Road and South African Brands, which David Jones' current parent company owns,

- cutting costs,

- focusing on fewer brands,

- focusing on highly knowledgeable and personalized services and customer loyalty programs,

- differentiating through product range,

- increasing online sales from $4 \%$ to $10 \%$ by 2020 ,

- opening up 10 new stores and replacing its 20year-old legacy systems with new merchandise planning and finance systems,

- moving to a single customer loyalty program to boost sales and margins,

- $\quad$ implementing a premium food strategy, initially with food services while fresh and prepared meal catalogues are built,

- $\quad$ having a single view of the customer across the business and merging David Jones and Country Road's sourcing and distribution systems.

Meanwhile David Jones' opportunities ${ }^{12,14,20,31,38,39,40,41}$ include the following: 
- $\quad$ There is a large opportunity for sales growth based on current low online sales.

- David Jones can operate an online market place for small and medium retailers in Australia and overseas.

- In addition to the David Jones American Express card, more financial products and services can be developed by establishing more strategic partnerships with financial institutions.

- More product and service categories and options and better customer services and experience can be developed.

- David Jones has initiatives of focusing on premier personalized shopping experiences, engaging and entertaining customers, and supplying top quality food services. These initiatives could also be an effective weapon to defend against aggressive attacks by its pure online counterparts.

- David Jones has established a couple of focused sites including David Jones Wine Club, David Jones Flowers, and Bridal at David Jones. More niche/focused initiatives could be pursued in the future. Meanwhile more B2B initiatives could be explored. In addition, David Jones could work on $\mathrm{C} 2 \mathrm{C}$ online platforms for trading second-hand David Jones products. Also, David Jones could have a separate website for clearance items. Just like other department stores, there could be one dedicated location or floor for out-of-season products.

- Opportunities in overseas markets: David Jones opened its first international store in 2016 in New Zealand, and it is reported that a few more new stores will be opened in New Zealand, where its current parent company South African Retailer Woolworth has already established operations (i.e., supermarkets). In the future, other international markets (especially Asian Pacific regions) should be pursued. Consumers in Chinese and other Asian markets are more willing to spend on high quality products and services and top end international brands from reputable overseas retailers. In order to capitalize on such opportunities, David Jones needs to develop its website and applications in multiple/local languages and adopt the approach of GLOCOL (i.e., the combined approach of globalization and localization).
- $\quad$ Attracting more age groups: David Jones focuses on the middle-age group since it is an upmarket department store, but it should not ignore younger generations since it also sells products and services needed for younger generations. The key is to create different tailored messages and experiences for different age groups.

- There are opportunities for mobile business for location based marketing and advertising, near field communication (NFC) payment. Opportunities of social business should be pursued to link social sites with online shopping.

- Opportunities arising from the combination of technology and traditional retail: In the future, the physical store will be more for experience, brand exposure, and creating moments for impulse buying, and staff in the physical store will focus on providing more value-added services and knowledge to the customers. The future shopping experience will be a combination of technology and traditional shopping.

- Opportunities arising from Big Data and Analytics: David Jones could do better at collecting, analyzing and utilizing information about their customers to understand their needs and shopping patterns.

- Opportunities arising from the declining Australian dollar and the proposed tax on overseas purchases below A $\$ 1,000$. Currently, low-value goods, (customs value of $\mathrm{A} \$ 1,000$ or less) are exempted from GST. Pending Australian legislation will impose the GST liability on overseas vendors who sell more than A $\$ 75,000$ of low-value goods to Australian consumers. These factors favour Australian retailers including online retailers.

- David Jones could extend its single-sided online platforms to multi-sided platforms to attract more stakeholders and create more opportunities for value creation.

- Including all transaction activities in an 'all-in-one' package could provide more value-added services to customers.

- David Jones currently targets middle-to-upper income customers but could also generate revenues from low income customers by setting up separate subsidiaries (online and offline) similar 
some major airlines which also own independent cheaper airlines.

- David Jones could explore Amazon.com, eBay.com, Alibaba.com, and JD.com for more domestic and international exposures and businesses. On 16 June 2017, Amazon announced it was buying Whole Foods to move deeper into the massive, non-cyclical grocery business.

- Opportunities to lock-in customers with its own brands and/or well-known Australian brands.

- Opportunities in acquiring complementary businesses, assets, and technologies.

- $\quad$ Establish more international strategic partners and necessary offline presences if David Jones wants to achieve sustainable international growth.

\subsection{Success Factors of E-tailing}

Some success factor of e-tailing ${ }^{42}$ include:

- product category choices/selections, which are organized in an effective way so customers could easily find them via recommendation systems;

- $\quad$ effective pricing strategies;

- $\quad$ reliable, secure, useful, user friendly, and dynamic e-tailing site with adequate, accurate and up-todate content and information;

- $\quad$ effective and efficient supply chains with respect to hassle free return policies and practices plus convenient pick-up points at multiple and easyaccess locations;

- multiple-channel strategy or "omni-channel" strategy with senior management's commitment and organizational efforts as well a strategy to deal with channel conflict;

- excellent customer services;

- excellent capabilities of order fulfillment and issue resolution;

- $\quad$ consistent experience and communication across multiple channels, touch points, and devices;

- $\quad$ trust, brand awareness, and good reputation;

- strategic alliances with suppliers, resellers, affiliates, logistics firms, global marketing platforms, telecommunication operators, technology vendors, government agencies, industry associations, global credit card and payment firms, international couriers and domestic couriers, HR agencies, stakeholders of the organization's business ecosystems, and many others.
David Jones should assess its business in terms of the success factors and identify other factors to lock in their customers in the long term.

\section{Conclusions}

The competition from online counterparts has forced David Jones to establish effective Internet-based operations for long-term survival and sustainable growth. It is argued that a retailer using technology to enhance retailing experience and expand online and/or in-store sales may never be able to beat a technology company expanding into retail. ${ }^{43}$ Based on this argument, David Jones will not be a winner in the future unless it turns itself into a technology firm or at least technology-focused firm. Besides technology, David Jones may win by having more automated warehouses/fulfillment centers and faster shipping. ${ }^{44}$

Instead of matching the prices of its online counterparts, David Jones needs to educate themselves regarding doing business online, invest in technology, enhance their ability to understand their customers, continuously address people's needs, deliver excellent and personalized customer experience arising from better collecting and understanding customer data, develop efficient and effective global supply chains for multiple channel services, encourage innovation and invest in research and development, be fast in adopting new technology, have effective and dynamic e-tailing sites, and work on differentiation as well as having the mentality of investing into the future and not focusing on short-term gains to survive and succeed in the disruptive and highly competitive world of etailing. . $^{4,45,13}$

So what is the future or the likelihood of future success for David Jones? Strengths of and opportunities for David Jones to ultimately succeed or increase the chances of success include: (1) David Jones has a long and established history and brand, existing business networks, rich retail experience, and established customer base and loyalty; (2) Its new management team seems to have better management skills and experience and have suggested more sensible strategy and action plans for David Jones; (3) The global phenomenon of mobility and connectedness enable mobile commerce; (4) David Jones has established relations with customers, suppliers and partners; (5) other opportunities included in Section 4.1. 
Conversely, weaknesses of David Jones and risks on its road to success include: (1) competition and threats discussed in Section 2; (2) weaknesses discussed in Section 3; (3) it may be vulnerable to the economic conditions and currency exchange changes; (4) the world may become flatter dominated by a few big players who will not necessarily come from the retail sector.

David Jones may look reasonably sound right now. It can become a successful and sustainable online business by means of innovation (e.g. Google and Amazon), building business ecosystems (like Alibaba, Amazon), developing global supply chains (e.g. Amazon's dragon boat project), and creating cloud platforms (e.g. Google and Amazon). For future survival and growth, David Jones should understand the role of the Internet technology in businesses. The Internet and digital technologies stand to deliver innovative solutions that has not been previously considered.

\section{References}

1. Ecommerce Foundation, Global B2C E-commerce Report 2016. online available at https://www.ecommercewiki.org/ wikis/www.ecommercewiki.org/images/5/56/Global_B2C Ecommerce_Report_2016.pdf. (accessed 29 June 2017).

2. David Jones, The Story of David Jones, 2016. online available at https://www.davidjones.com.au/About-DavidJones/The-Story-of-David-Jones (accessed 30 April 2017).

3. E. Greenblat, "David Jones outpaces flat fashion market, lifts profit sharply", The Australian, August 25, 2016. online available at http://www.theaustralian.com.au/ business/companies/david-jones-outpaces-flat-fashionmarket-more-than-doubles-profit/news-story/49d75226ef3 9575924b39ac230b8dfc6 (accessed 10 January 2017).

4. Wikipedia, David Jones Limited, 1 May 2017. online, available at https://en.wikipedia.org/wiki/ David_Jones_Limited (accessed 20 May 2017).

5. A. Robertson, "Myer and David Jones have been making time for years, do they have a future", ABC News, 23 September 2016. online available at http:// www.abc.net.au/news/2016-09-23/myer-and-david-jonesmark-time/7873144 (accessed 20 February 2017).

6. A. Robertson, "Myer raid could trigger David Jones merger: Analyst", ABC News, 30 March 2017. online, available at http://www.abc.net.au/news/2017-0329/could-myer-raid-trigger-david-jones-merger/8396516 (accessed 5 May 2017).

7. R. Schultes, "The future for retail giant David Jones", The Saturday Paper, 27 August 2016. online available at https://www.thesaturdaypaper.com.au/business/2016/08/2 7/the-future-retail-giant-david-jones/14722200003641 (accessed 1 March 2017).
8. C. Low, "David Jones earnings fall despite sales growth", The Sydney Morning Herald, 11 February 2016. online available at http://www.smh.com.au/business/retail/davidjones-earnings-fall-despite-sales-growth-20160211gmr7m4.html (accessed 10 January 2017).

9. J. Cohen, "Containing the Amazon offensive", Retail Inside, May 25, 2017. online, available at https://www.insideretail.com.au/blog/2017/05/25/containi ng-the-amazon-offensive/ (accessed 6 June 2017).

10. Inside Retail, "Slow deliveries hurting Aussie ecommerce", Inside Retail, 16 May 2017. online available at https://www.insideretail.com.au/blog/2017/05/16/slowdeliveries-hurting-aussie-e-commerce/ (accessed 27 May 2017).

11. R. Montgomery, "Watch out retailers: Here comes Amazon", Companies, rogermontgomery.com, 3 April 2017. online available at https://rogermontgomery.com/ watch-out-retailers-here-comes-amazon/ (accessed 5 May 2017).

12. D. McCauley, "We got it badly wrong, David Jones parent company Woolworths Holdings boss Ian Moir admits", news.com.au, 22 February 2017. online available at: http://www.news.com.au/finance/business/retail/davidjones-unveils-firsthalf-profit-of-150-million/newsstory/30f9e006e4e5b5e725b3e93ebb79518b (accessed 10 March 2017).

13. D. Sotiropoulos, "Debt and Amazon: A perfect storm", Inside Retail, 10 March 2017. online available at https://www.insideretail.com.au/blog/2017/03/10/debtand-amazon-a-perfect-storm/ (accessed 20 April 2017).

14. A. Keane, "Australia's middle class shrinks as property creates great divide", Daily Telegraph, 29 July 2016. online, available at http://www.dailytelegraph.com.au/ business/australias-middle-class-shrinks-as-propertycreates-great-divide/news-story/ (accessed 8 June 2017).

15. S. Mitchell, "Woolworths tweaks private label at David Jones", Australian Financial Review, 17 February 2017. online, available at http:/www.afr.com/business/ retail/woolworths-tweaks-private-label-at-david-jones20170216-guf3hs (accessed 30 March 2017).

16. CBA (Commonwealth Bank of Australia), Media Release, More Online Retailers Set to Open Physical Stores to Drive Sales, 16 July 2016. online available at https://www.commbank.com.au/guidance/newsroom/onlin e-retailers-physical-stores-201607.html (accessed 20 January 2017).

17. eMarketer, "Worldwide Retail Ecommerce Sales Will Reach \$1.915 Trillion This Year", Retail \& Ecommerce, August 22, 2016. online available at https://www. emarketer.com/Article/Worldwide-Retail-EcommerceSales-Will-Reach-1915-Trillion-This-Year/1014369 (accessed 20 February 2017).

18. A. Bainbridge, "More than 50 per cent of Australians shopping online: Roy Morgan research", News, Australian Broadcasting Corporation (ABC), 4 June 2013. online available at http://www.abc.net.au/news/2013-06- 
04/more-than-50-per-cent-of-australians-shoppingonline/4731590 (accessed 20 January 2017).

19. S. Canning, "Formidable Amazon's Entry to Australia would improve etail across board say retailer", Mumbrella, 21 February 2016. online available at https://mumbrella.com.au/tropfest-crowdfunding-attemptfalls-woefully-short-348020 (accessed 20 March 2017).

20. G. Mortimer, "Amazon in Australia might not be the end of retail as we know it", The Conversation, 30 March 2017. online, available at http://theconversation.com/ amazon-in-australia-might-not-be-the-end-of-retail-as-weknow-it-75382 (accessed 28 April 2017).

21. M. Doble, "Property trusts: what could go wrong (Part 3The Amazon Threat)", Review: Insight from Real Estate Experts, 8 May 2017. online available at http:// blog.apngroup.com.au/property-trusts-what-could-gowrong-part-3-the-amazon-threat/ (accessed 10 June 2017).

22. CBA (Commonwealth Bank of Australia), Media Release, Australia retail innovation report card, 27 March 2017. online, available at https://www.commbank.com.au/ guidance/newsroom/Australian-retail-innovation-reportcard-201703.html (accessed 10 April 2017).

23. Deloitte Access Economics, Retail Forecasts-May 2017, Retail risk review: China, Housing \& Amazon, Media Release, Deloitte Access Economics, 14 June 2017. online available at https://www2.deloitte.com/au/en/pages/mediareleases/articles/retail-forecasts.html (accessed 15 June 2017).

24. A. Arnold, "Amazon may be coming to Australia, so what does that mean for you", News, Australian Broadcasting Corporation $(A B C), 24$ February 2017. online available at http://www.abc.net.au/news/2017-02-24/what-doesamazons-imminent-arrival-in-australia-mean-foryou/8297084 (accessed 10 March 2017).

25. S. Mitchell and M. Smith, "Myer-David Jones merger won't work, say analyst", The Sydney Morning Herald, 31 January 2014. online available at http:// www.smh.com.au/business/retail/myer--david-jonesmerger-wont-work-say-analysts-20140131-31qzq.html (accessed 15 January 2017).

26. N. Ahmed, S. Mitchell and J. Chessell, "Myer sought merger of equals with rival David Jones", The Sydney Morning Herald, 30 January 2014. online available at http://www.smh.com.au/business/retail/myer-soughtmerger-of-equals-with-rival-david-jones-2014013031pj0.html (accessed 15 January 2017).

27. J. Murphy, "What Myer needs to do to turn it all around", news.com.au, 1 April 2017. online available at http://www.news.com.au/finance/business/retail/whatmyer-needs-to-do-to-turn-it-all-around/newsstory/c0cace2f2d8fbc1f61bc026375633989 (accessed 10 May 2017).

28. M. Smith, "Myer-David Jones merger make sense, says major shareholder", The Sydney Morning Herald, 31 January 2014. online available at http://www.smh.com.au/ business/retail/myerdavid-jones-merger-makes-sense- says-major-shareholder-20140130-31q6t.html (accessed 15 January 2017).

29. M. Neems, "ACCC to jeep close eye on Myer, David Jones merger plans", The Australian, 21 February 2014. online available at http://www.theaustralian.com.au/ business/mergers-acquisitions/accc-to-keep-close-eye-onmyer-david-jones-merger-plans/news-

story/2366786004cfe024577cab2d635b4fbc (accessed 15 January 2017).

30. D. McCauley, "David Jones Ambitious $\$ 100$ million plan to become Australia's top food destination", news.com.au, 26 August 2016. online available at http://www.news.com. au/finance/business/retail/david-jones-ambitious-100million-plan-to-become-australias-top-food-destination/ news-story/818b0069ed2d88c53a85226d33575b1a (accessed 12 January 2017).

31. S. Mitchell, "David Jones' interstate move triggers staff exodus", Australian Financial Review, 2 March 2017. online, available at http://www.afr.com/business/ retail/david-jones-interstate-move-triggers-staff-exodus20170302-guoxyk (accessed 30 March 2017).

32. M. Robin, "David Jones and Myer Slide into irrelevance: Why our department stores are falling", Managing Smart Company, 19 February 2013. online available at http://www.smartcompany.com.au/people-humanresources/managing/david-jones-and-myer-slide-intoirrelevance-why-our-department-stores-are-failing/ (accessed 15 January 2017).

33. A. Zaczkiewicz, "Amazon, Wal-Mart Lead Top 25 Ecommerce Retail List", $W W D$, March 7, 2016. online available at http://wwd.com/business-news/financial/ amazon-walmart-top-ecommerce-retailers-10383750/ (accessed 20 January 2017).

34. Productreview, David Jones Review, 2017. online available at $\mathrm{http} / / / \mathrm{www}$. productreview.com.au/p/davidjones.html (accessed 15 June 2017).

35. Seek, Company Reviews, David Jones, 2017. online, available at https://www.seek.com.au/companies/davidjones-432327 (accessed 15 June 2017).

36. Fin24, "Woolies CEO: Department store isn't dead", Fin24, April 9, 2014. online available at http://www.fin24.com/Companies/Retail/Woolies-CEODepartment-store-isnt-dead-20140409 (accessed 8 May 2017).

37. S. Mitchell, "Woolworths bolsters David Jones team", The Sydney Morning Herald, 10 February 2015. online, available at: http://www.smh.com.au/business/retail/ woolworths-bolsters-david-jones-team-20150209-

13adu4.html?promote_channel $=$ edmail\&mbnr $=\% \%=$ Repl ace(Base64Encode(AccountId), $\% 27=\% 27, \% 27 \% 27)=\% \%$ (accessed 3 March 2017).

38. H. McNab, "David Jones unveils $\$ 50 \mathrm{~m}$ Elizabeth St store facelift", Daily Telegraph, 13 April 2017. online available at: http://www.dailytelegraph.com.au/newslocal/centralsydney/david-jones-unveils-50m-elizabeth-st-storefacelift/news-story/89f7b28979429e6fd8070607a70d4079 (accessed 28 April 2017). 
39. Inside Retail, "David Jones to open new store at Wollongong Central", Inside Retail, 23 May 2016. online, available at: https://www.insideretail.com.au/blog/2016/05/23/davidjones-to-open-new-store-at-wollongong-central/ (accessed 20 January 2017).

40. NPR (National Public Radio) Staff, "A Portrait of America's Middle Class, By the Numbers", NPR, July 7, 2016. online available at http://www.npr.org/2016/07/07/ 484941939/a-portrait-of-americas-middle-class-by-thenumbers (accessed 2 May 2017).

41. M. Gerdes, "Speed Meets Variety in Amazon's Deal for Whole Foods", strategy+business, June 16, 2017. online available at https://www.strategy-business.com/ blog/Speed-Meets-Variety-in-Amazons-Deal-for-WholeFoods?gko $=6 \mathrm{c} 1 \mathrm{a} 2 \& u t m \_s o u r c e=i t w \& u t m \_$medium $=2017$ 0620\&utm_campaign $=$ resp (accessed 21 June 2017).
42. J. Xu, Managing Digital Enterprise: Ten Essential Topics, 2014. Atlantis Press \& Springer.

43. P. Mourdoukoutas, P. 2017, "Walmart will never beat Amazon", Forbes, May 19, 2017. online available at https://www.forbes.com/sites/panosmourdoukoutas/2017/0 5/19/walmart-will-never-beat-amazon/\#3634819ed32e (accessed 25 May 2017).

44. N. Bose, "Wal-Mart's next move against Amazon: More warehouses, faster shipping", Technology News, October 6, 2016. online available at http://www.reuters.com/ article/us-walmart-ecommerce-idUSKCN12609P (accessed 2 May 2017).

45. J. Norton, "How Australian retailers can prepare for the arrival of Amazon", Australian Retailers Association Blog, 26 April 2017. online available at http://blog.retail.org.au/newsandinsights/how-australianretailers-can-prepare-for-the-arrival-of-amazon (accessed 20 May 2017). 